\title{
Luteolin Molekülü Covid-19 ile Mücadelede Bir Seçenek Olabilir mi?
}

\author{
Fatime Betül ÜZER \\ Sağlık Bilimleri Üniversitesi Hamidiye Sağlık Bilimleri Enstitüsü, \\ Fitoterapi Anabilim Dalı, İstanbul, Türkiye
}

Sorumlu Yazar / Corresponding Author: Fatime Betül ÜZER, e-posta: uzerbetul@gmail.com

\section{ÖZET}

SARS-CoV-2 tüm dünyayı etkisi altına alan ve inhibisyonuna yönelik henüz kesin bir tedavi yöntemi geliştirilememiş bir virüstür. Mevcut tedavi protokolleri yeterli çözüm ortaya koyamamıştır. Virüs inhibisyonuna yönelik yapılan moleküler docking çalışmalarında doğal ürünler arasında Luteolin molekülü öne çıkmaktadır. Luteolin molekülü, Origanum vulgare, Apium graveolens, Thymus vulgaris başta olmak üzere birçok bitkide doğal olarak bulunan bir moleküldür. Luteolin, İran, Brezilya ve geleneksel Çin Tıbbında enflamasyon ile devam eden hastalıkların tedavisinde uzun süredir kullanılagelmiştir. Antioksidan, antimikrobial, antienflamatuar, kemopreventif, kemoterapötik, kardioprotektif, antidiabetik, nöroprotektif ve antialerjik özelliklere sahip, termostabil bir moleküldür. Luteolin molekülü SARS-CoV-2'nin hücre içine girerken kullandığı furin bağlanma bölgesine bağlanarak, virüsün hücre içine girmesini engelleyebilir. Mevcut kullanım alanları, etki mekanizmaları, SARS-CoV-2 patofizyolojisi ve moleküler docking çalışmaları birlikte değerlendirildiğinde, Covid-19 ile mücadelede Luteolin molekülü umut verici bir terapötik ajan olarak öne çıkmaktadır.

\section{Could Luteolin Molecule be an Option in Combating Covid-19?}

\begin{abstract}
SARS-CoV-2 is a virus that has affected the whole world and a definitive treatment method for its inhibition has not yet been developed. Current treatment protocols have not been able to provide a sufficient solution. As a result of molecular docking studies for virus inhibition, it is seen that the Luteolin molecule stands out among natural products. Luteolin molecule is a molecule found naturally in many plants, especially Origanum vulgare, Apium graveolens, Thymus vulgaris. Luteolin has long been used in Iran, Brazil, and traditional Chinese Medicine to treat illnesses with inflammation. It is a thermostable molecule with antioxidant, antimicrobial, anti-inflammatory, chemopreventive, chemotherapeutic, cardioprotective, antidiabetic, neuroprotective and antiallergic properties. The luteolin molecule can bind to the furin binding site that SARS-CoV-2 uses to enter the cell, thereby preventing the virus from entering the cell. When the current usage areas, mechanisms of action, SARSCoV-2 pathophysiology and molecular docking studies are evaluated, Luteolin molecule stands out as a promising therapeutic agent in the fight against Covid-19.
\end{abstract}

Key words: SARS-CoV-2, Covid-19, Luteolin, Furin, Natural product 
Journal of Integrative and Anatolian

Medicine

Bütünleyici ve Anadolu Tıbbı Dergisi
Cilt/ Volume: 2 Sayı / Issue: 3

Yli/Year: 2021
Yayıncı / Publisher

Sağllk Bilimleri Üniversitesi University of Health Sciences

\section{GíRIŞ}

SARS-CoV-2 olarak isimlendirilen bir çeşit koronavirüs 2019 Aralık ayında, Çin'in Hubei eyaletine bağlı Wuhan şehrinde akut atipik solunum yolu enfeksiyonlarına neden olmaya başladı. $\mathrm{Bu}$ virüsün neden olduğu hastalık COVID-19 olarak adlandırıldı. Virüs primer olarak solunum sistemini ve daha sonra tüm organları tutabilmekte, hastalarda baș ağrısı, baș dönmesi, halsizlik, ateş, mide bulantısı, ishal, koku kaybı, tat kaybına sebep olabilmekte, tablo ölümle seyredebilmektedir (Chen vd., 2020). İnsandan insana bulaşan ve tüm dünyada pandemiye neden olan koronavirüs nedeniyle 25 Haziran 2021 tarihi itibariyle dünya çapında 179.686.071 kişi hastalandı, 3.899.172 kişi hayatını kaybetti, 2.624.733.776 kişi aşılandı. Dünya Sağlık Örgütü tarafından Azithromycin, colchicine, corticosteroid, favipiravir, hydroxychloroquine, interferon beta, lopinavirritonavir, remdesivir, rhG-CSF, tocilizumab, umifenovir Covid-19 hastaları üzerinde kullanılan ilaçlar olarak bildirilmiştir ("World Health Organisation," n.d.). Ancak bu ilaçlar kesin bir tedavi yaklaşımı ortaya koyamamakta. Mevcut medikal yaklaşım, hastalığın ilerlemiş aşamalarında yetersiz kalmaktadır.

SARS-CoV-2'nin de dahil olduğu koronavirüsler zarflı, tek iplikli RNA virüsleridir (Channappanavar, Zhao, \& Perlman, 2014). Genomik yapılarına göre 4 türe ayrılırlar; $\alpha, \beta, \gamma$ koronavirüsler sadece memelileri enfekte eder (Rabi, Al Zoubi, Al-Nasser, Kasasbeh, \& Salameh, 2020). SARS-CoV-2, $\quad \beta$ koronavirüslerdendir. Virüsün yaşam döngüsü 5 evreden oluşur: Bağlanma, penetrasyon, biosentez, maturasyon ve ayrılma. Virüs konak hücre reseptörlerine bağlandıktan sonra, endositoz ve membran füzyonu yolu ile hücreye girer. Viral içeriğin konak hücreye salınımından sonra, viral RNA replikasyon için çekirdeğin içine girer. Viral mRNA, viral proteinleri yapmak için kullanılır. Sonrasında viral partiküller oluşturulup, salınır. Koronavirüsler 4 yapısal proteinden oluşur. Spike (S), Membrane (M), envelope (E), ve nükleokapsid (N) (Bosch, van der Zee, de Haan, \& Rottier, 2003). Spike proteini, 2 fonksiyonel alt birimden oluşur; $S_{1}$ alt birimi konak hücre reseptörüne ve $\mathrm{S}_{2}$ alt birimi viral ve hücresel membranlara bağlanmakla sorumludur. Anjiotensin dönüştürücü enzim 2 (ACE2), SARS-CoV-2 için fonksiyonel bir reseptördür ( $\mathrm{Li}$ vd., 2003). Yapısal ve fonksiyonel analizler SARS-CoV-2 Spike proteininin ACE2'ye bağlandığını göstermiştir. Akciğer, kalp, ileum, böbrek ve mesanede ACE2 ekspresyonu fazladır. ACE2 reseptörleri Akciğer epitel hücrelerinde yüksek miktarda bulunur (Chen, Guo, Pan, \& Zhao, 2020). Virüs ACE2'ye bağlanmadan önce Furin Proteaz ve Transmembran Serin Proteaz enzimleri ile bağlanmaya hazır hale getirilmelidir. Bu nedenle virüsün hücre içine girerken kullandığ 1 Anjiotensin Converting Enzim 2, Furin Proteaz ve Transmembran Serin Proteaz, SARS-CoV2'nin hücre içine girişini engelleyen farmakolojik hedefler olabilir (Tian vd., 2021).

\section{SARS-CoV-2 Patofizyolojisinden Yola Çıkarak Covid-19 Tedavisine Yaklaşım}

Virüs konak hücreye bağlandıktan sonra proteaz enzimi virüsün $\mathrm{S} 1$ ve $\mathrm{S} 2$ alt birimlerini bağlayan kovalent bağ1 çözer, S1 alt birimi S2'nin hücreye bağlanmasına yardımcı olur. Tüm virüsler içinde korona virüs spike proteini farklı bir öneme sahiptir. $\mathrm{Bu}$ protein birçok farklı proteaz enzimi ile etkileşime girer ve aktive olur. SARS-CoV-2 diğer koronavirüslerden farklı olarak S1 ve S2 alt birimleri arasında furin kırılma bölgesine sahiptir (RPPA). Bu kırılma bölgesinin iyi eksprese olması virüsü diğer koronavirüslerden daha patojen hale getirir (Walls vd., 2020).

ACE2, Akciğerin apikal bölgesindeki alveol epitel hücrelerinde yoğun miktarda eksprese edilir. $\mathrm{Bu}$ yüzden birçok hastada distal solunum yolu hasarı görülmüştür. Epitel hücreleri, alveolar makrofajlar ve dendritik hücreler solunum yollarının 3 ana bileşenidir (Yoshikawa, Hill, Li, Peters, \& Tseng, 2009). Dendritik hücreler (DC) epitelin altında, Makrofajlar epitelin apikalinde bulunur (Hamming vd., 2004). Dendritik hücre ve makrofajlar bağışıklık sistemi uyarlanana kadar virüslere karşı doğal bağışıklık hücreleri olarak hizmet eder. T hücresi yanıtı DC'ler ve makrofajlar yoluyla antijen 
sunumu ile başlatılır. DC ve makrofajlar virüs bulaşmış apoptotik hücreleri fagosite edebilir ve bu da $\mathrm{T}$ hücrelerine antijen sunumuna yol açar. Antijen sunan hücreler $\mathrm{T}$ hücrelerine antijen sunmak için lenf bezlerine göç eder. Burada CD4 ve CD8 T hücreleri kritik öneme sahiptir. CD4 T hücreleri virüslere özgü antikor üretimini indüklemek için B hücrelerini aktive eder, CD8 T hücreleri ise virüsle enfekte olmuş hücreleri öldürür. Şiddetli hastalık tablosunda monosit kemo-çekici protein 1 (MCP1), makrofaj enflamatuar protein (MIP) ve tümör nekroz faktörü (TNF $\alpha)$ artar (Zhou vd., 2020). Enfeksiyonu şiddetli geçiren hastalarda IL6 düzeylerinin yüksek olduğu görülmüştür. $\mathrm{Bu}$ hastalarda CD4 ve CD8 T hücreleri aktivasyonu ve yüksek oranda CD69, CD38 ve CD44 ekspresyonu tespit edilmiştir. Hastalığın ağır seyrettiği hastalarda $\mathrm{T}$ hücrelerinin tükendiği ortaya konmuştur. $\mathrm{T}$ hücrelerinin tükenmesi hastalığın ilerlemesine yol açabilirdi. Bir diğer ilginç bulgu hastalığı ağır geçiren vakalarda CD4 $\mathrm{T}$ hücreleri, IFN-Y ve GM-CSF'nin birlikte görülmesiydi (Zhou vd., 2020).

SARS-CoV-2 enfeksiyon patofizyolojisi incelendiğinde, virüsle başa çıkabilmenin en önemli yollarından birinin furin proteaz inhibisyonu ile virüsün ACE2 reseptörlerine bağlanıp, hücre içine girmesini engellemek olduğu görülür. Tenesse Üniversitesi ve Oak Ridge Ulusal Laboratuarları tarafindan yapılan bir araştırmada SARS-CoV-2'nin hücrelere bağlanması sırasında bazı bileşiklerin etkinliğini modellemek için IBM süper bilgisayar programları kullanılarak bir çalışma yapıldı. Moleküler Docking yöntemiyle etkinlik sırasına göre bileşikler listelendi. Bu listede iyi derecede etkinlikte 4 tane doğal ürün de bulunmaktaydı. Etkinlik derecesine göre bu doğal ürünler luteolin-monoarabinosid, Kuersetin, eriodictiol, demetil-koklaurin olarak sıralanmıştı (Micholas \& Jeremy C., 2020).

$\mathrm{Yu}$ ve arkadaşları AutoDock Vina kullanarak yaptıkları bir başka moleküler docking çalışmasında SARS-CoV-2 ile Ribavirin, Remdesivir, Chloro-quine ve Luteolin moleküllerini değerlendirdi. Çalışma sonucunda
Chloro-quinin klinik olarak efektif olduğu ve Luteolinin dikkate değer potansiyel bir antiviral molekül olduğu sonucuna vardılar (Yu, Chen, Lan, Shen, \& Li, 2020). Moleküler docking yöntemleriyle yapılan bu çalışmalarda, doğal ürünler arasında en iyi etkinliğe sahip olduğu tespit edilen luteolinin, furin proteaz inhibisyonuna sebep olduğu Zhu ve arkadaşlarının 2013'te yaptıkları çalışma ile de ortaya konmuştu (Zhu vd., 2013). SARS-CoV2'nin diğer koronavirüslerden farklı olarak S1 ve S2 alt birimleri arasında Furin kırılma bölgesi bulunmaktadir (Yuki, Fujiogi, \& Koutsogiannaki, 2020). Bu durum luteolini virüs inhibisyonunda değerli hale getirmektedir.

Peng ve arkadaşlarının Deng Humması çalışmasında insan furin enziminin (1 ünite) katalitik aktivitesi, 5 ila $200 \mu \mathrm{M}^{\prime}$ lik konsantrasyon aralığında luteolin kullanılarak, $100 \mu \mathrm{M}$ sabit konsantrasyondaki substrat üzerinde test edildi. Enzim aktivitesinin ( $>\% 95)$ maksimum inhibisyonu $200 \mu \mathrm{M}$ konsantrasyonda gerçekleşti. Peng ve arkadaşları yaptıkları çalışmada luteolinin viremiyi azalttığını, IL6 düzeylerinde azalmaya neden olduğunu da tespit etti (Peng vd., 2017).

Xagorari ve arkadaşları ise luteolinin IL6 produksiyonunu ve endotoksin tarafindan aktive edilmiş makrofajlar vasıtasıyla TNF $\alpha$ salınımını inhibe ettiğini tespit etti (Xagorari vd., 2001).

SARS-CoV-2 ile enfekte olmuş birçok hastada gelişen sitokin firtınası neticesinde şok, çoklu organ yetmezliği, fulminan miyokardit ve ölüm rapor edilmiştir (Rabi vd., 2020; Ruan, Yang, Wang, Jiang, \& Song, 2020; F. Zhou vd., 2020; Zhou vd., 2020). SARS-CoV-2 enfeksiyonu ve sonrasında birçok hastada gelişen sitokin firtınasının neticeleri değerlendirildiğinde Covid19 ile mücadelede luteolin destek tedavisi öne çıkmaktadır. Zira Luteolin SARS-CoV-2'yi diğer koronavirüslerden daha enfekte hale getiren furin kırılma bölgesinin enzimi furin proteazı inhibe ederek; IL6, TNF $\alpha$ düzeylerini azaltarak Covid19 üzerinde etkili olabilir (Lin, Shi, Wang, \& Shen, 2008; Peng vd., 2017; Xagorari vd., 2001). 
Journal of Integrative and Anatolian Medicine

Bütünleyici ve Anadolu Tıbbı Dergisi
Cilt/ Volume: 2 Sayı / Issue: 3 Yll/Year: 2021
Yayıncı / Publisher

Sağllk Bilimleri Üniversitesi University of Health Sciences

\section{Luteolin ve Kullanım Alanları}

Luteolin (3',4',5,7-tetrahydroxy flavone), birçok bitki türünde bulunan önemli bir flavondur (Choi vd., 2014). Kimyasal olarak 2 benzen halkası ve bir oksijen içeren, bir adet C2-C3 çift karbon bağına sahip C6-C3-C6 yapısında bir moleküldür (Bravo, 2009). Yap1 aktivite çalışmaları luteolin molekülünün $5,7,3$ ' ve 4' pozisyonlarında bulunan hidroksil grupları ve 23 çift bağ varlığının çoklu farmakolojik etkilerinden sorumlu olduğunu göstermiştir (Lin vd., 2008).

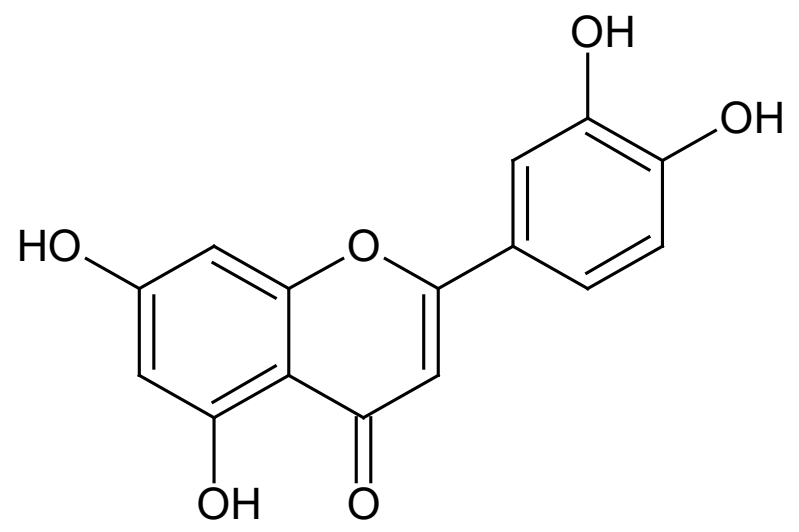

Şekil 1: Luteolin molekülünün kimyasal yapısı

Doğal halde glikozillenmiş formda bulunan Luteolin brokoli, biber, dağ kekiği, kereviz gibi sebze ve meyvelerde mevcuttur (Lopez-Lazaro, 2008). İran, Brezilya ve geleneksel Çin Tıbbında enflamasyon ile birlikte devam eden hastalıkların tedavisinde uzun süredir kullanılagelmiştir (Farzaei, Abbasabadi, Ardekani, Rahimi, \& Farzaei, 2013; Ferrari vd., 2013; Ramezani, Nasri, \& Yassa, 2009).

Luteolin, antioksidan, antimikrobial, antienflamatuar, kemopreventif, kemoterapötik, kardioprotektif, antidiabetik, nöroprotektif ve antialerjik özelliklere sahip, termostabil bir moleküldür (Ahmed vd., 2019; Andarwulan, Batari, Sandrasari, Bolling, \& Wijaya, 2010; Franke, Custer, Arakaki, \& Murphy, 2004; Hertog, Hollman, \& Venema, 1992; HoffmannRibani, Huber, \& Rodriguez-Amaya, 2009; Pellegrini vd., 2010; Tuorkey, 2016).
Yapı-biyoaktivite ilişkisinin incelendiği bir çalışmada Zhu ve arkadaşları Luteolin, kuersetin ve kateşin moleküllerini kıyasladıklarında luteolinin daha düşük O-H bağ ayrışma enerjisine sahip olduğunu, dolayısıyla daha güçlü bir antioksidan olduğunu tespit etti (L. Zhu, Chen, Tan, Liu, \& Wang, 2017).

In vitro ve in vivo çalışmalar, luteolin'in NFкB, AP-1 ve JAK-STAT yolağını düzenleyebildiğini göstermiştir. Luteolin'in hem in vitro hem de in vivo enflamatuar hastalık modellerinde fayda sağladı̆̆ gösterilmiştir (Lou vd., 2015; Nunes, Almeida, Barbosa, \& Laranjinha, 2017).

Luteolinin terapötik kullanım alanları oldukça geniştir. Nöroprotektif, antilaşmanyal, antidiabetik, antialerjik, anti-akciğerfibrozis, antidiyabetik, kardiyoprotektif özellikleri bildirilmiştir (Ahmed vd., 2019).

Luteolinin oral skuamöz hücreli kanser, akciğer kanseri, kolon kanseri, özafagial kanser, hepatosellüler kanser ve prostat kanserine karş1 koruyucu etkileri yapılan farklı çalışmalarda tespit edilmiştir (Cao vd., 2018; P. Chen vd., 2017; Han vd., 2016; Jiang vd., 2018; Kang vd., 2017; S. F. Yang, Yang, Chang, Chu, \& Hsieh, 2008). Meme kanserinde koruyucu ve tedavi edici etkileri bildirilmiştir (Ahmed vd., 2019).

Luteolin, kan beyin bariyerini geçebildiği için beyin tümörü gibi santral sinir sistemi hastalıklarında kullanılabilir (Kashyap vd., 2017). Alzheimer enflamasyonla seyreden nörodejeneratif bir hastalık olduğu için luteolin koruyucu ve tedavi edici olarak kullanılabilir (Kwon, 2017).

Coleta ve arkadaşları fareler üzerinde yaptıkları çalışmada luteolinin oral ve intraperitonal uygulaması sonucunda molekülün anksiyolitik etkisini tespit etti (Coleta, Campos, Cotrim, Lima, \& Cunha, 2008). 4-10 yaşları arasında otizmli 50 çocukla yapılan bir çalışmada 26 hafta boyunca günlük $100 \mathrm{mg}$ luteolin ve 70 mg kuersetin takviyesi sonucunda uyumsal işlevlerde anlamlı bir iyileşme kaydedildi (Taliou, Zintzaras, Lykouras, \& Francis, 2013). 
Journal of Integrative and Anatolian Medicine

Bütünleyici ve Anadolu Tıbbı Dergisi
Cilt/ Volume: 2 Sayı / Issue: 3

Yil/Year: 2021
Yayınc1 / Publisher Sağllk Bilimleri Üniversitesi University of Health Sciences
Yapılan çalışmalar luteolinin oksidatif stres, nöroenflamasyon, glial aktivasyonu azaltarak ve nörotrofik potansiyeli indükleyerek dopaminerjik nöronları koruyabildiğini göstermektedir. $\mathrm{Bu}$ özellikleri nedeniyle parkinsonda da koruyucu ve tedavi edici olarak kullanılabilir $(\mathrm{Hu}, \mathrm{Yen}$, Shen, Wu, \& Wu, 2014; Patil vd., 2014). Luteolinin muhtemel toksikolojik etkileri üzerine sinırlı sayıda çalışma yapılmıştır. Mukinda ve arkadaşları Luteolin bakımından zengin Artemisia afra'nın kemirgenler üzerinde akut ve kronik kullanımı sonucunda herhangi bir toksisite bulgusuna rastlamadi (Mukinda, 2005). Ancak bu konuyla ilgili daha fazla çalışmaya ihtiyaç vardır.

Tablo 1. Bazı Bitkilerde Tespit Edilen Luteolin Miktarları (Kuru Bitki)

\begin{tabular}{|c|c|c|}
\hline Bitki & $\begin{array}{l}\text { Luteolin } \\
\text { miktarı }\end{array}$ & Referans \\
\hline Lippia graveolens & 10287,5 & $\begin{array}{l}\text { (Lin, Mukhopadhyay, Robbins, } \\
\text { \& Harnly, 2007) }\end{array}$ \\
\hline Appium graveolens (tohum) & 7624 & (Lin, Lu, \& Harnly, 2007) \\
\hline Arachis hypogea & 4260,67 & (Hindarto vd., 2017) \\
\hline Capsicum frutescens & 1035 & (Miean \& Mohamed, 2001) \\
\hline Angelica keiskei & 950 & (Yang vd., 2008) \\
\hline Capsicum annuum & 530 & (Yang vd., 2008) \\
\hline Averrhoa belimbi (yapraklar) & 464,5 & (Miean \& Mohamed, 2001) \\
\hline Allium fistulosum & 391 & (Miean \& Mohamed, 2001) \\
\hline Phyla nodiflora & 390 & (Yang vd., 2008) \\
\hline Asystasia gangetica & 277 & (Yang vd., 2008) \\
\hline Vernonia hymenolepis & 240 & (Yang vd., 2008) \\
\hline Averrhoa belimbi (meyve) & 202 & (Miean \& Mohamed, 2001) \\
\hline Petroselinum crispum & 197,5 & (Lugasi \& Hóvári, 2002) \\
\hline Rosmarinus officinalis & 184 & (Yang vd., 2008) \\
\hline Wedelia chinensis & 128 & (Yang vd., 2008) \\
\hline Garcinia atroviridus & 107,5 & (Miean \& Mohamed, 2001) \\
\hline Lonicera japonica & 90 & (Yang vd., 2008) \\
\hline Brassica oleracea & 74,5 & (Miean \& Mohamed, 2001) \\
\hline Scaevola sericea & 73 & (Yang vd., 2008) \\
\hline Sonchus oleraceus L. & 65 & (Trichopoulou vd., 2000) \\
\hline Taraxacum officinale & 62 & (Yang vd., 2008) \\
\hline Sorghum bicolor (L.) Moench (k1rmızı) & 39,3 & $\begin{array}{l}\text { (Dykes, Seitz, Rooney, \& } \\
\text { Rooney, 2009) }\end{array}$ \\
\hline Capsicum annum & 33 & (Miean \& Mohamed, 2001) \\
\hline Citrus hystrix & 30,5 & (Miean \& Mohamed, 2001) \\
\hline Adansonia digitata & 16 & (Yang vd., 2008) \\
\hline Raphanus sativus & 9 & (Miean \& Mohamed, 2001) \\
\hline Tordylium apulum (yaprak) & 6 & (Trichopoulou vd., 2000) \\
\hline Passiflora foetida & 5 & (Yang vd., 2008) \\
\hline Sorghum bicolor (L.) Moench (beyaz) & 4,5 & (Dykes vd., 2009) \\
\hline
\end{tabular}


Journal of Integrative and Anatolian Medicine

Bütünleyici ve Anadolu Tıbbı Dergisi
Cilt/ Volume: 2 Sayı / Issue: 3

Yl1/Year: 2021
Yayınc1 / Publisher

Sağllk Bilimleri Üniversitesi University of Health Sciences

\section{Luteolin İçeren Bitkiler}

Miean ve arkadaşları 62 çeşit bitki üzerinde yaptıkları çalışmada bazı bitkilerdeki flavonoid miktarlarını bitkilerin kuru ağırlıkları üzerinden tespit ettiler. Yaptıkları çalışmada bitkilerdeki luteolin miktarları şöyleydi:

Brassica oleracea: $74.5 \mathrm{mg} / \mathrm{kg}$ (kuru ağırlık), Capsicum annum: $33.0 \mathrm{mg} / \mathrm{kg}$, Capsicum frutescens: $1035.0 \mathrm{mg} / \mathrm{kg}$, Allium fistulosum: $391.0 \mathrm{mg} / \mathrm{kg}$, Averrhoa belimbi (meyve): $202.0 \mathrm{mg} / \mathrm{kg}$, Averrhoa belimbi (yapraklar): 464,5 mg/kg, Phaseolus vulgaris: $11.0 \mathrm{mg} / \mathrm{kg}$, Daucus carota: $37.5 \mathrm{mg} / \mathrm{kg}$, Raphanus sativus: $9.0 \mathrm{mg} / \mathrm{kg}$, Apium graveolens: $80.5 \mathrm{mg} / \mathrm{kg}$, Citrus hystrix (yapraklar): 30.5 $\mathrm{mg} / \mathrm{kg}$, Garcinia atroviridus: $107.5 \mathrm{mg} / \mathrm{kg}$ (Miean \& Mohamed, 2001).

Yang ve arkadaşları ise 91 çeşit bitki üzerinde yaptıkları çalışmada bazı bitkilerdeki luteolin miktarlarını şöyle tespit ettiler:Angelika keiskei filizleri: $950 \mathrm{mg} / \mathrm{kg}$, Scaevola sericea filizleri: $73 \mathrm{mg} / \mathrm{kg}$, Apium graveolens kökü: 10 $\mathrm{mg} / \mathrm{kg}$, Capsicum annuum kökü: $530 \mathrm{mg} / \mathrm{kg}$, Asystasia gangetica kökü: $127 \mathrm{mg} / \mathrm{kg}$, Wedelia chinensis kökü: $128 \mathrm{mg} / \mathrm{kg}$, Taraxacum officinale kökü: $62 \mathrm{mg} / \mathrm{kg}$, Phyla nodiflora kökü: 184 $\mathrm{mg} / \mathrm{kg}$, Vernonia hymenolepis kökü: $240 \mathrm{mg} / \mathrm{kg}$, Passiflora foetida kökü: $5 \mathrm{mg} / \mathrm{kg}$ (Yang vd., 2008).

Hindarto ve arkadaşları yer fistığ1 kabuklarından (Arachis hypogea) 4260,67 mg/kg luteolin elde ettiler (Hindarto vd., 2017). Elde ettikleri luteolin miktarı Radhakrishnan ve arkadaşlarının Kore yer fistığından elde ettiği $546.8-4485.0 \mathrm{mg} / \mathrm{kg}$ luteolin miktarına benzerdi (Ramalingam, Suk Bok, Byoung Kyu, \& In Youl, 2013).

Tablo 2: Bazı Bitkilerde Tespit Edilen Luteolin Miktarları (mg/kg Taze Bitki)

\begin{tabular}{|c|c|c|}
\hline Bitki ismi & $\begin{array}{c}\text { Luteolin } \\
\text { miktarı }\end{array}$ & Referans \\
\hline $\begin{array}{l}\text { Juniperus } \\
\text { (olgunlaşmış) }\end{array}$ & 690,5 & (Innocenti vd., 2007) \\
\hline $\begin{array}{ll}\text { Juniperus } & \text { communis } \\
\text { (olgunlaşmamış) }\end{array}$ & 514 & (Innocenti vd., 2007) \\
\hline Thymus vulgaris & 452 & $\begin{array}{l}\text { (Justesen \& Knuthsen, 2001), (Wojdyło, Oszmiański, } \\
\text { \& Czemerys, 2007) }\end{array}$ \\
\hline Daucus carota & 341 & (Trichopoulou vd., 2000) \\
\hline Lippia graveolens & 250,1 & (Wojdyło vd., 2007) \\
\hline Salvia officinalis & 167 & (Justesen \& Knuthsen, 2001), (Wojdyło vd., 2007) \\
\hline Mentha x piperita L. & 126,6 & (Areias vd., 2001), (Justesen \& Knuthsen, 2001) \\
\hline Capsicum frutescens & 38,7 & $\begin{array}{l}\text { (Bahorun, Luximon-Ramma, Crozier, \& Aruoma, } \\
\text { 2004) }\end{array}$ \\
\hline Cichorium intybus & 37,98 & (Innocenti vd., 2005) \\
\hline Cynara scolymus & 23 & $\begin{array}{l}\text { (Lattanzio \& van Sumere, 1987), (Schütz vd., 2004), } \\
\text { (Wang vd., 2003) }\end{array}$ \\
\hline Cichorium intybus & 20,8 & $\begin{array}{l}\text { (Arabbi, Genovese, \& Lajolo, 2004), (Michael vd., } \\
\text { 1992), (Innocenti vd., 2005) }\end{array}$ \\
\hline Rosmarinus officinalis & 20 & (Justesen \& Knuthsen, 2001), (Wojdyło vd., 2007) \\
\hline Citrus limon & 19 & $\begin{array}{l}\text { (Lugasi \& Hóvári, 2002), (Mattila, Astola, \& } \\
\text { Kumpulainen, 2000) }\end{array}$ \\
\hline Cucurbita spp & 16,3 & (Lugasi \& Hóvári, 2002) \\
\hline
\end{tabular}


Journal of Integrative and Anatolian Medicine

Bütünleyici ve Anadolu Tıbbı Dergisi
Cilt/ Volume: 2 Sayı / Issue: 3

Yl1/Year: 2021
Yayınc1 / Publisher

Sağlk Bilimleri Üniversitesi University of Health Sciences

\begin{tabular}{|c|c|c|}
\hline Bitki ismi & $\begin{array}{c}\text { Luteolin } \\
\text { miktarı }\end{array}$ & Referans \\
\hline Capsicum anuum & 13,4 & (Materska \& Perucka, 2005) \\
\hline $\begin{array}{l}\text { (Brassica oleracea } \\
\text { (Gongylodes Group) }\end{array}$ & 13 & (Lugasi \& Hóvári, 2000) \\
\hline Petroselinum crispum & 10,9 & $\begin{array}{l}\text { (Arai vd., 2000), (Justesen \& Knuthsen, 2001), } \\
\text { (Justesen, Knuthsen, \& Leth, 1998) }\end{array}$ \\
\hline Origanum vulgare & 10 & (Justesen \& Knuthsen, 2001) \\
\hline Artemisia dranunculus & 10 & (Justesen \& Knuthsen, 2001) \\
\hline Lactuca sativa var. Crispa & 9,5 & $\begin{array}{l}\text { (Arabbi vd., 2004), (Harnly vd., 2006), (Young vd., } \\
\text { 2005) }\end{array}$ \\
\hline Armoracia rusticana & 9 & (Lugasi \& Hóvári, 2000) \\
\hline Brassica oleracea var. italica & 8 & $\begin{array}{l}\text { (Arai vd., 2000), (Bahorun vd., 2004), (Franke vd., } \\
\text { 2004), (Harnly vd., 2006) }\end{array}$ \\
\hline Cucumis melo & 6,4 & $\begin{array}{l}\text { (Harnly vd., 2006), (Lugasi \& Hóvári, 2002), } \\
\text { (Sampson vd., 2002) }\end{array}$ \\
\hline Citrus paradisi & 6 & (Harnly vd., 2006), (Franke vd., 2004) \\
\hline Tordylium apulum & 6 & (Trichopoulou vd., 2000) \\
\hline Citrullus lanatus & 4,6 & $\begin{array}{l}\text { (Arai vd., 2000), (Harnly vd., 2006), (Lugasi \& } \\
\text { Hóvári, 2002), (Sampson vd., 2002) }\end{array}$ \\
\hline Beta vulgaris & 3,7 & (Hertog vd., 1992), (Lugasi \& Hóvári, 2000) \\
\hline Nelumbo nucifera & 3,6 & (Arai vd., 2000) \\
\hline Brassica oleracea & 3,3 & $\begin{array}{l}\text { Hertog vd., 1992), (Pellegrini vd., 2010), (Lugasi \& } \\
\text { Hóvári, 2000) }\end{array}$ \\
\hline Citrus sinensis & 1,9 & $\begin{array}{l}\text { (Arai vd., 2000), (Franke vd., 2004), (Lugasi \& } \\
\text { Hóvári, 2002) }\end{array}$ \\
\hline Allium schoenoprasum & 1,5 & $\begin{array}{l}\text { (Justesen \& Knuthsen, 2001), (Trichopoulou vd., } \\
\text { 2000) }\end{array}$ \\
\hline Phaseolus vulgaris & 1,3 & $\begin{array}{l}\text { (Arai vd., 2000), (Franke vd., 2004), (Hertog vd., } \\
\text { 1992) }\end{array}$ \\
\hline Daucus carota & 1,1 & $\begin{array}{l}\text { (Arai vd., 2000), (Bahorun vd., 2004), (Hertog vd., } \\
\text { 1992), (Lugasi \& Hóvári, 2000) }\end{array}$ \\
\hline lpomoea batatas & 1,1 & (Andarwulan vd., 2010), (Franke vd., 2004) \\
\hline Brassicaoleracea var. viridis & 0,8 & (Young vd., 2005) \\
\hline
\end{tabular}

\section{SONUÇ}

Luteolin, yapılan pek çok çalışmada antienflamatuar, antimikrobiyal, antikanser, nöroprotektif özellikleri kanıtlanmış olan bir moleküldür. SARS-CoV-2'ye yönelik moleküler docking çalışmalarında, doğal moleküller arasında, luteolin molekülü öne çıkmaktadır.
Covid-19 ile mücadelede, luteolin SARS-CoV2'yi diğer koronavirüslerden daha enfekte hale getiren furin kırılma bölgesinin enzimi furin proteazı inhibe ederek; IL6, TNF $\alpha$ düzeylerini azaltarak etkili olabilir. 
Journal of Integrative and Anatolian Medicine

Bütünleyici ve Anadolu Tıbbı Dergisi
Cilt/ Volume: 2 Sayı / Issue: 3

Yil/Year: 2021
Yayınc1 / Publisher

Sağllk Bilimleri Üniversitesi University of Health Sciences
Luteolin ile ilgili bu makalemizin, SARSCoV-2'nin luteolin ile inhibisyonuna yönelik in vitro, in vivo, klinik çalışmalar ve luteolinin muhtemel toksik etkileri ile ilgili araştırmaların önünü açmasını temenni ediyoruz.

\section{KAYNAKLAR}

Ahmed, S., Khan, H., Fratantonio, D., Hasan, M. M., Sharifi, S., Fathi, N., ... Rastrelli, L. (2019). Apoptosis induced by luteolin in breast cancer: Mechanistic and therapeutic perspectives. Phytomedicine.

https://doi.org/10.1016/j.phymed.2019.152883

Andarwulan, N., Batari, R., Sandrasari, D. A., Bolling, B., \& Wijaya, H. (2010). Flavonoid content and antioxidant activity of vegetables from Indonesia. Food Chemistry. https://doi.org/10.1016/j.foodchem.2010.01.033

Arabbi, P. R., Genovese, M. I., \& Lajolo, F. M. (2004). Flavonoids in Vegetable Foods Commonly Consumed in Brazil and Estimated Ingestion by the Brazilian Population. Journal of Agricultural and Food Chemistry. https://doi.org/10.1021/jf0499525

Arai, Y., Watanabe, S., Kimira, M., Shimoi, K., Mochizuki, R., \& Kinae, N. (2000). Dietary Intakes of Flavonols, Flavones and Isoflavones by Japanese Women and the Inverse Correlation between Quercetin Intake and Plasma LDL Cholesterol Concentration. The Journal of Nutrition. https://doi.org/10.1093/jn/130.9.2243

Areias, F. M., Valentão, P., Andrade, P. B., Ferreres, F., \& Seabra, R. M. (2001). Phenolic fingerprint of peppermint leaves. Food Chemistry, 73(3), 307311. https://doi.org/10.1016/S03088146(00)00302-2

Bahorun, T., Luximon-Ramma, A., Crozier, A., \& Aruoma, O. I. (2004). Total phenol, flavonoid, proanthocyanidin and vitamin $\mathrm{C}$ levels and antioxidant activities of Mauritian vegetables. Journal of the Science of Food and Agriculture. https://doi.org/10.1002/jsfa.1820

Bosch, B. J., van der Zee, R., de Haan, C. A. M., \& Rottier, P. J. M. (2003). The Coronavirus Spike Protein Is a Class I Virus Fusion Protein: Structural and Functional Characterization of the Fusion Core Complex. Journal of Virology. https://doi.org/10.1128/jvi.77.16.8801-8811.2003
Bravo, L. (2009). Polyphenols: Chemistry, Dietary Sources, Metabolism, and Nutritional Significance. Nutrition Reviews. https://doi.org/10.1111/j.17534887.1998.tb01670.x

Cao, Z., Zhang, H., Cai, X., Fang, W., Chai, D., Wen, Y., ... Zhang, Y. (2018). Luteolin Promotes Cell Apoptosis by Inducing Autophagy in Hepatocellular Carcinoma. Cellular Physiology and Biochemistry. https://doi.org/10.1159/000484066

Channappanavar, R., Zhao, J., \& Perlman, S. (2014). T cellmediated immune response to respiratory coronaviruses. Immunologic Research. https://doi.org/10.1007/s12026-014-8534-z

Chen, N., Zhou, M., Dong, X., Qu, J., Gong, F., Han, Y., ... Zhang, L. (2020). Epidemiological and clinical characteristics of 99 cases of 2019 novel coronavirus pneumonia in Wuhan, China: a descriptive study. The Lancet. https://doi.org/10.1016/S0140-6736(20)30211-7

Chen, P., Zhang, J. Y., Sha, B. B., Ma, Y. E., Hu, T., Ma, Y. C., ... Li, P. (2017). Luteolin inhibits cell proliferation and induces cell apoptosis via downregulation of mitochondrial membrane potential in esophageal carcinoma cells EC1 and KYSE450. Oncotarget.

https://doi.org/10.18632/oncotarget.15832

Chen, Y., Guo, Y., Pan, Y., \& Zhao, Z. J. (2020). Structure analysis of the receptor binding of 2019-nCoV. Biochemical and Biophysical Research Communications. https://doi.org/10.1016/j.bbrc.2020.02.071

Choi, S.-M., Kim, B. C., Cho, Y.-H., Choi, K.-H., Chang, J., Park, M.-S., ... Kim, J.-K. (2014). Effects of Flavonoid Compounds on $\beta$-amyloid-peptideinduced Neuronal Death in Cultured Mouse Cortical Neurons. Chonnam Medical Journal. https://doi.org/10.4068/cmj.2014.50.2.45

Coleta, M., Campos, M. G., Cotrim, M. D., Lima, T. C. M. d., \& Cunha, A. P. da. (2008). Assessment of luteolin $\quad\left(3^{\prime}, 4^{\prime}, 5,7\right.$-tetrahydroxyflavone $)$ neuropharmacological activity. Behavioural Brain Research. https://doi.org/10.1016/j.bbr.2007.12.010

Dykes, L., Seitz, L. M., Rooney, W. L., \& Rooney, L. W. (2009). Flavonoid composition of red sorghum 
Journal of Integrative and Anatolian Medicine

Bütünleyici ve Anadolu Tıbbı Dergisi
Cilt/ Volume: 2 Sayı / Issue: 3 Yll/Year: 2021
Yayıncı / Publisher

Sağllk Bilimleri Üniversitesi University of Health Sciences genotypes. Food Chemistry. https://doi.org/10.1016/j.foodchem.2009.02.052

Farzaei, M. H., Abbasabadi, Z., Ardekani, M. R. S., Rahimi, R., \& Farzaei, F. (2013). Parsley: a review of ethnopharmacology, phytochemistry and biological activities. Journal of Traditional Chinese Medicine. https://doi.org/10.1016/s02546272(14)60018-2

Ferrari, F. C., Ferreira, L. C., Souza, M. R., GrabeGuimarães, A., Paula, C. A., Rezende, S. A., \& Saúde-Guimarães, D. A. (2013). Antiinflammatory sesquiterpene lactones from lychnophora trichocarpha spreng. (Brazilian Arnica). Phytotherapy Research. https://doi.org/10.1002/ptr.4736

Franke, A. A., Custer, L. J., Arakaki, C., \& Murphy, S. P. (2004). Vitamin C and flavonoid levels of fruits and vegetables consumed in Hawaii. Journal of Food Composition and Analysis. https://doi.org/10.1016/S0889-1575(03)00066-8

Hamming, I., Timens, W., Bulthuis, M. L. C., Lely, A. T., Navis, G. J., \& van Goor, H. (2004). Tissue distribution of ACE2 protein, the functional receptor for SARS coronavirus. A first step in understanding SARS pathogenesis. Journal of Pathology. https://doi.org/10.1002/path.1570

Han, K., Meng, W., Zhang, J. J., Zhou, Y., Wang, Y. L., Su, Y., Min, D. L. (2016). Luteolin inhibited proliferation and induced apoptosis of prostate cancer cells through miR-301. OncoTargets and Therapy. https://doi.org/10.2147/OTT.S102862

Harnly, J. M., Doherty, R. F., Beecher, G. R., Holden, J. M., Haytowitz, D. B., Bhagwat, S., \& Gebhardt, S. (2006). Flavonoid content of U.S. fruits, vegetables, and nuts. Journal of Agricultural and Food

Chemistry.

https://doi.org/10.1021/jf061478a

Hertog, Michael G.L., Hollman, P. C. H., Hertog, M. G. L., \& Katan, M. B. (1992). Content of Potentially Anticarcinogenic Flavonoids of 28 Vegetables and 9 Fruits Commonly Consumed in the Netherlands. Journal of Agricultural and Food Chemistry. https://doi.org/10.1021/jf00024a011

Hertog, Michaël G.L., Hollman, P. C. H., \& Venema, D. P. (1992). Optimization of a Quantitative HPLC Determination of Potentially Anticarcinogenic Flavonoids in Vegetables and Fruits. Journal of

\section{Agricultural and Food Chemistry. https://doi.org/10.1021/jf00021a023}

Hindarto, C. K., Lestari, E. S., Irawan, C., \& Rochaeni, H. (2017). Antioxidant activity of luteolin extracted from nutshell waste Arachis Hypogea. Int $J$ Res Pharm Pharm Sci, 2(6), 28-30.

Hoffmann-Ribani, R., Huber, L. S., \& Rodriguez-Amaya, D. B. (2009). Flavonols in fresh and processed Brazilian fruits. Journal of Food Composition and Analysis.

https://doi.org/10.1016/j.jfca.2008.12.004

Hu, L. W., Yen, J. H., Shen, Y. T., Wu, K. Y., \& Wu, M. J. (2014). Luteolin modulates 6-hydroxydopamineinduced transcriptional changes of stress response pathways in PC12 cells. PLoS ONE. https://doi.org/10.1371/journal.pone.0097880

Innocenti, M., Gallori, S., Giaccherini, C., Ieri, F., Vincieri, F. F., \& Mulinacci, N. (2005). Evaluation of the phenolic content in the aerial parts of different varieties of Cichorium intybus L. Journal of Agricultural and Food Chemistry. https://doi.org/10.1021/jf050541d

Innocenti, M., Michelozzi, M., Giaccherini, C., Ieri, F., Vincieri, F. F., \& Mulinacci, N. (2007). Flavonoids and biflavonoids in tuscan berries of Juniperus communis L.: Detection and quantitation by HPLC/DAD/ESI/MS. Journal of Agricultural and Food Chemistry. https://doi.org/10.1021/jf070257h

Jiang, Z. Q., Li, M. H., Qin, Y. M., Jiang, H. Y., Zhang, X., \& Wu, M. H. (2018). Luteolin inhibits tumorigenesis and induces apoptosis of non-small cell lung cancer cells via regulation of microRNA34a-5p. International Journal of Molecular Sciences. https://doi.org/10.3390/ijms19020447

Justesen, U., \& Knuthsen, P. (2001). Composition of flavonoids in fresh herbs and calculation of flavonoid intake by use of herbs in traditional Danish dishes. Food Chemistry. https://doi.org/10.1016/S0308-8146(01)00114-5

Justesen, U., Knuthsen, P., \& Leth, T. (1998). Quantitative analysis of flavonols, flavones, and flavanones in fruits, vegetables and beverages by highperformance liquid chromatography with photodiode array and mass spectrometric detection. Journal of Chromatography A. https://doi.org/10.1016/S0021-9673(97)01061-3 
Journal of Integrative and Anatolian Medicine

Bütünleyici ve Anadolu Tıbbı Dergisi
Cilt/ Volume: 2 Sayı / Issue: 3

Yll/Year: 2021
Yayıncı / Publisher

Sağllk Bilimleri Üniversitesi University of Health Sciences
Kang, K. A., Piao, M. J., Ryu, Y. S., Hyun, Y. J., Park, J. E., Shilnikova, K., ... Hyun, J. W. (2017). Luteolin induces apoptotic cell death via antioxidant activity in human colon cancer cells. International Journal of Oncology. https://doi.org/10.3892/ijo.2017.4091

Kashyap, D., Sharma, A., Tuli, H. S., Sak, K., Punia, S., \& Mukherjee, T. K. (2017). Kaempferol - A dietary anticancer molecule with multiple mechanisms of action: Recent trends and advancements. Journal of Functional Foods. https://doi.org/10.1016/j.jff.2017.01.022

Kwon, Y. (2017). Luteolin as a potential preventive and therapeutic candidate for Alzheimer's disease. Experimental Gerontology. https://doi.org/10.1016/j.exger.2017.05.014

Lattanzio, V., \& van Sumere, C. F. (1987). Changes in phenolic compounds during the development and cold storage of artichoke (Cynara scolymus L.) heads. Food Chemistry. https://doi.org/10.1016/0308-8146(87)90082-3

Li, W., Moore, M. J., Vasllieva, N., Sui, J., Wong, S. K., Berne, M. A., ... Farzan, M. (2003). Angiotensinconverting enzyme 2 is a functional receptor for the SARS coronavirus. Nature. https://doi.org/10.1038/nature02145

Lin, L. Z., Lu, S., \& Harnly, J. M. (2007). Detection and quantification of glycosylated flavonoid malonates in celery, chinese celery, and celery seed by LC-DAD-ESI/MS. Journal of Agricultural and Food Chemistry. https://doi.org/10.1021/jf0624796

Lin, L. Z., Mukhopadhyay, S., Robbins, R. J., \& Harnly, J. M. (2007). Identification and quantification of flavonoids of Mexican oregano (Lippia graveolens) by LC-DAD-ESI/MS analysis. Journal of Food Composition and Analysis. https://doi.org/10.1016/j.jfca.2006.09.005

Lin, Y., Shi, R., Wang, X., \& Shen, H.-M. (2008). Luteolin, a Flavonoid with Potential for Cancer Prevention and Therapy. Current Cancer Drug Targets. https://doi.org/10.2174/156800908786241050

Lopez-Lazaro, M. (2008). Distribution and Biological Activities of the Flavonoid Luteolin. MiniReviews in Medicinal Chemistry. https://doi.org/10.2174/138955709787001712
Lou, L., Liu, Y., Zhou, J., Wei, Y., Deng, J., Dong, B., \& Chai, L. (2015). Chlorogenic acid and luteolin synergistically inhibit the proliferation of interleukin-1 $\quad \beta \quad$-induced fibroblast-like synoviocytes through regulating the activation of NF- B and JAK/STAT-signaling pathways. Immunopharmacology and Immunotoxicology. https://doi.org/10.3109/08923973.2015.1095763

Lugasi, A., \& Hóvári, J. (2000). Flavonoid aglycons in foods of plant origin I. vegetables. Acta Alimentaria. https://doi.org/10.1556/AAlim.29.2000.4.4

Lugasi, A., \& Hóvári, J. (2002). Flavonoid aglycons in foods of plant origin II. Fresh and dried fruits. Acta Alimentaria. https://doi.org/10.1556/AAlim.31.2002.1.7

Materska, M., \& Perucka, I. (2005). Antioxidant activity of the main phenolic compounds isolated from hot pepper fruit (Capsicum annuum L.). Journal of Agricultural and Food Chemistry, 53(5), 17501756. https://doi.org/10.1021/jf035331k

Mattila, P., Astola, J., \& Kumpulainen, J. (2000). Determination of flavonoids in plant material by HPLC with diode-array and electro-array detections. Journal of Agricultural and Food Chemistry. https://doi.org/10.1021/jf000661f

Micholas, S., \& Jeremy C., S. (2020). Repurposing Therapeutics for COVID-19: SupercomputerBased Docking to the SARS-CoV-2 Viral Spike Protein and Viral Spike Protein-Human ACE2 Interface.

ChemRxiv. https://doi.org/10.26434/chemrxiv.11871402.v4

Miean, K. H., \& Mohamed, S. (2001). Flavonoid (myricetin, quercetin, kaempferol, luteolin, and apigenin) content of edible tropical plants. Journal of Agricultural and Food Chemistry. https://doi.org/10.1021/jf000892m

Mukinda, J. T. (2005). Acute and chronic toxicity of the flavonoid- containing plant, Artemisia afra in rodents Keywords. University of Western Cape (MSc Dissertation).

Nunes, C., Almeida, L., Barbosa, R. M., \& Laranjinha, J. (2017). Luteolin suppresses the JAK/STAT pathway in a cellular model of intestinal inflammation. Food and Function. https://doi.org/10.1039/c6fo01529h 
Journal of Integrative and Anatolian Medicine

Bütünleyici ve Anadolu Tıbbı Dergisi
Cilt/ Volume: 2 Sayı / Issue: 3

Yll/Year: 2021
Yayıncı / Publisher

Sağllk Bilimleri Üniversitesi University of Health Sciences
Patil, S. P., Jain, P. D., Sancheti, J. S., Ghumatkar, P. J., Tambe, R., \& Sathaye, S. (2014). Neuroprotective and neurotrophic effects of Apigenin and Luteolin in MPTP induced parkinsonism in mice. Neuropharmacology. https://doi.org/10.1016/j.neuropharm.2014.07.01 2

Pellegrini, N., Chiavaro, E., Gardana, C., Mazzeo, T., Contino, D., Gallo, M., Porrini, M. (2010). Effect of different cooking methods on color, phytochemical concentration, and antioxidant capacity of raw and frozen brassica vegetables. Journal of Agricultural and Food Chemistry. https://doi.org/10.1021/jf904306r

Peng, M., Watanabe, S., Chan, K. W. K., He, Q., Zhao, Y., Zhang, Z., ... Li, G. (2017). Luteolin restricts dengue virus replication through inhibition of the proprotein convertase furin. Antiviral Research. https://doi.org/10.1016/j.antiviral.2017.03.026

Rabi, F. A., Al Zoubi, M. S., Al-Nasser, A. D., Kasasbeh, G. A., \& Salameh, D. M. (2020). Sars-cov-2 and coronavirus disease 2019: What we know so far. Pathogens.

https://doi.org/10.3390/pathogens9030231

Ramalingam, R., Suk Bok, P., Byoung Kyu, L., \& In Youl, B. (2013). Evaluation of luteolin from shells of Korean peanut cultivars for industrial utilization. African Journal of Biotechnology. https://doi.org/10.5897/ajb2013.12911

Ramezani, M., Nasri, S., \& Yassa, N. (2009). Antinociceptive and anti-inflammatory effects of isolated fractions from Apium graveolens seeds in mice. Pharmaceutical Biology. https://doi.org/10.1080/13880200902939283

Ruan, Q., Yang, K., Wang, W., Jiang, L., \& Song, J. (2020). Clinical predictors of mortality due to COVID-19 based on an analysis of data of 150 patients from Wuhan, China. Intensive Care Medicine. https://doi.org/10.1007/s00134-020-05991-x

Sakakibara, H., Honda, Y., Nakagawa, S., Ashida, H., \& Kanazawa, K. (2003). Simultaneous determination of all polyphenols in vegetables, fruits, and teas. Journal of Agricultural and Food Chemistry. https://doi.org/10.1021/jf0209261

Sampson, L., Rimm, E., Hollman, P. C. H., De Vries, J. H. M., \& Katan, M. B. (2002). Flavonol and flavone intakes in US health professionals. Journal of the

\section{American Dietetic Association. https://doi.org/10.1016/S0002-8223(02)90314-7}

Schütz, K., Kammerer, D., Carle, R., \& Schieber, A. (2004). Identification and quantification of caffeoylquinic acids and flavonoids from artichoke (Cynara scolymus L.) heads, juice, and pomace by HPLC-DAD-ESI/MSn. Journal of Agricultural and Food Chemistry. https://doi.org/10.1021/jf049625x

Taliou, A., Zintzaras, E., Lykouras, L., \& Francis, K. (2013). An open-label pilot study of a formulation containing the anti-inflammatory flavonoid luteolin and its effects on behavior in children with autism spectrum disorders. Clinical Therapeutics. https://doi.org/10.1016/j.clinthera.2013.04.006

Tian, D., Liu, Y., Liang, C., Xin, L., Xie, X., Zhang, D., ... Cao, W. (2021). An update review of emerging small-molecule therapeutic options for COVID19. Biomedicine \& Pharmacotherapy = Biomedecine \& Pharmacotherapie, 137, 111313. https://doi.org/10.1016/j.biopha.2021.111313

Trichopoulou, A., Vasilopoulou, E., Hollman, P., Chamalides, C., Foufa, E., Kaloudis, T., ... Theophilou, D. (2000). Nutritional composition and flavonoid content of edible wild greens and green pies: A potential rich source of antioxidant nutrients in the Mediterranean diet. Food Chemistry. https://doi.org/10.1016/S03088146(00)00091-1

Tuorkey, M. J. (2016). Molecular targets of luteolin in cancer. European Journal of Cancer Prevention. https://doi.org/10.1097/CEJ.0000000000000128

Walls, A. C., Park, Y. J., Tortorici, M. A., Wall, A., McGuire, A. T., \& Veesler, D. (2020). Structure, Function, and Antigenicity of the SARS-CoV-2 Spike Glycoprotein. Cell. https://doi.org/10.1016/j.cell.2020.02.058

Wang, M., Simon, J. E., Aviles, I. F., He, K., Zheng, Q. Y., \& Tadmor, Y. (2003). Analysis of antioxidative phenolic compounds in artichoke (Cynara scolymus L.). Journal of Agricultural and Food Chemistry. https://doi.org/10.1021/jf020792b

Wojdyło, A., Oszmiański, J., \& Czemerys, R. (2007). Antioxidant activity and phenolic compounds in 32 selected herbs. Food Chemistry. https://doi.org/10.1016/j.foodchem.2007.04.038 
Journal of Integrative and Anatolian Medicine

Bütünleyici ve Anadolu Tıbbı Dergisi
Cilt/ Volume: 2 Sayı / Issue: 3 Yll/Year: 2021
Yaynci / Publisher

Sağllk Bilimleri Üniversitesi University of Health Sciences
World Health Organisation. (n.d.). Retrieved February 6, 2021, from https://www.who.int/publications/m/item/draftlandscape-of-covid-19-candidate-vaccines

Xagorari, A., Papapetropoulos, A., Mauromatis, A., Economou, M., Fotsis, T., \& Roussos, C. (2001). Luteolin inhibits an endotoxin-stimulated phosphorylation cascade and proinflammatory cytokine production in macrophages. Journal of Pharmacology and Experimental Therapeutics.

Yang, R. Y., Lin, S., \& Kuo, G. (2008). Content and distribution of flavonoids among 91 edible plant species. Asia Pacific Journal of Clinical Nutrition. https://doi.org/10.6133/apjen.2008.17.s1.66

Yang, S. F., Yang, W. E., Chang, H. R., Chu, S. C., \& Hsieh, Y. S. (2008). Luteolin induces apoptosis in oral squamous cancer cells. Journal of Dental Research.

https://doi.org/10.1177/154405910808700413

Yoshikawa, T., Hill, T., Li, K., Peters, C. J., \& Tseng, C.T. K. (2009). Severe Acute Respiratory Syndrome (SARS) Coronavirus-Induced Lung Epithelial Cytokines Exacerbate SARS Pathogenesis by Modulating Intrinsic Functions of MonocyteDerived Macrophages and Dendritic Cells. Journal of Virology. https://doi.org/10.1128/jvi.01792-08

Young, J. E., Zhao, X., Carey, E. E., Welti, R., Yang, S. S., \& Wang, W. (2005). Phytochemical phenolics in organically grown vegetables. Molecular Nutrition and Food Research. https://doi.org/10.1002/mnfr.200500080

Yu, R., Chen, L., Lan, R., Shen, R., \& Li, P. (2020). Computational screening of antagonist against the
SARS-CoV-2 (COVID-19) coronavirus by molecular docking. International Journal of Antimicrobial Agents, 2(xxxx), 106012. https://doi.org/10.1016/j.ijantimicag.2020.106012

Yuki, K., Fujiogi, M., \& Koutsogiannaki, S. (2020). COVID-19 pathophysiology: A review. Clinical Immunology, 108427. https://doi.org/10.1016/j.clim.2020.108427

Zhou, F., Yu, T., Du, R., Fan, G., Liu, Y., Liu, Z., ... Cao, B. (2020). Clinical course and risk factors for mortality of adult inpatients with COVID-19 in Wuhan, China: a retrospective cohort study. The Lancet. https://doi.org/10.1016/S01406736(20)30566-3

Zhou, Y., Fu, B., Zheng, X., Wang, D., Zhao, C., qi, Y., ... Wei, H. (2020). Pathogenic $T$ cells and inflammatory monocytes incite inflammatory storm in severe COVID-19 patients. National Science Review. https://doi.org/10.1093/nsr/nwaa041

Zhu, J., Van de Ven, W. J. M., Verbiest, T., Koeckelberghs, G., Chen, C., Cui, Y., \& Vermorken, A. J. M. (2013). Polyphenols Can Inhibit Furin In Vitro As A Result of the Reactivity of their Auto-oxidation Products to Proteins. Current Medicinal Chemistry. https://doi.org/10.2174/0929867311320060009

Zhu, L., Chen, J., Tan, J., Liu, X., \& Wang, B. (2017). Flavonoids from Agrimonia pilosa Ledeb: Free radical scavenging and DNA oxidative damage protection activities and analysis of bioactivitystructure relationship based on molecular and electronic structures. Molecules. https://doi.org/10.3390/molecules220301 